\title{
COMPARATIVE CHARACTERIZATION OF PLANTAIN PEEL, PAWPAW PEEL AND WATERMELON RIND USING FTIR
}

\author{
1*AKINYEMI O. P. ${ }^{2}$ AKINBOMI J. G., ${ }^{3}$ ABBEY D. M, \\ Chemical Engineering Department, Lagos State University \\ 1.poakinyemi@yahoo.com; ${ }^{2}$ jayju2004@yahoo.com; ${ }^{3}$ moyosoredorcas4@gmail.com \\ *Corresponding author: poakinyemi@yahoo.com
}

Received: $17^{\text {th }}$ December 2019

Accepted: $15^{\text {th }}$ January 2020

Published: 31 st March 2020

https://doi.org/10.47545/etrj.2020.5.1.054

\begin{abstract}
Attempts of researchers in the recent times to tackle various chemical processes problems, especially in adsorption had attracted the uses of agricultural wastes like banana peel, rice husk, etc as adsorbent for removal of oil from crude oil-contaminated water. The structures of these agricultural materials contribute greatly to their performance as adsorbent. This study was aimed at determining and comparing the functional groups and bonds present in the structures of agricultural wastes (plantain peel, pawpaw peel and watermelon rind) using Fourier Transform Infra Red (FTIR) spectroscopy. The samples of the plantain peel, pawpaw peel and watermelon rind were collected from Female hostel, Lagos State University, Epe campus, Lagos State, Nigeria. The adsorbents were prepared from agricultural waste materials by crushing them into powdery form after drying in the oven at temperature of $110^{\circ} \mathrm{C}$ until constant weight was attained. Each of the products from the agricultural waste was characterized using Agilent FTIR spectroscope (range: 4000-650). From the FTIR analysis, all the three products contained O-H stretching, O-H bending, $\mathrm{C}=\mathrm{C}$ stretching, $\mathrm{C}-\mathrm{H}$ stretching, $\mathrm{C}-\mathrm{H}$ bending and $\mathrm{C}-\mathrm{O}$ stretching functional groups which implied all the agricultural wastes contain hemicellulose, cellulose and pectin - important components of biological adsorbents. Comparatively, N-H was only found in plantain peel which implies that amine with this kind of functional group could only be found in the plantain peels. Similarly, $\mathrm{C}=\mathrm{O}$ functional group could be found in watermelon rind alone which implies that the watermelon rind contains specific hemicelluloses not in the other two products. Furthermore, it was observed that only plantain peel and pawpaw peel have the $\mathrm{C}-\mathrm{N}$ stretch and $\mathrm{C}=\mathrm{C}$ bend functional groups which implied pawpaw and plantain peels contain some amine and substituted alkenes compounds that are not present in the watermelon rind. These proven capacities of plantain peel, pawpaw peel and watermelon rind provides a favorable platform to researchers to work on and to come out with a sound technology applicable for removal of crude oil from crude oil contaminated water. The use of these native agricultural materials as adsorbents will lead to cost efficiency and reduce operational cost.
\end{abstract}

Keywords: Plantain peel, pawpaw peel, watermelon rind, adsorbent, FTIR

\section{INTRODUCTION}

Agricultural waste materials have been found to be environmentally friendly and economically viable alternative to activated carbon as adsorbent for treating crude oil contaminated water. Hence, various agricultural wastes like rice husk, banana peel, etc. have been investigated as adsorbents for the treatment of crude oil-contaminated water. The structures of these agricultural materials contribute greatly to their performance as adsorbent. The production of Plantain (Musa paradisiacal) generally known as a cooking banana in Nigeria as at 2017 was 3,164,878 tons [1]. The world production of plantain stood at 39,241,376 tons as at 2017 [1]. Pawpaw (Carica papaya) belongs to the Caricaceae family, which contains over 22 species in the genus Carica; it originates from the tropics of the Americans, southern Mexico, and neighboring Central America. Varieties of pawpaw are typical Maradol, wax pawpaw, Sunrise solo, mountain pawpaw, red royale f1 Kamiya (Hawaii), Mexican Red (Mexico), JS.22, pink solo, kapoho solo. Although all the varieties can be cultivated successfully in Nigeria, the popular varieties of pawpaw in Nigeria are pink solo, large maradol, JS.22, and red royale. Nigeria is the main producer of papaw in the African continent with 751,000 MT [1]. None of most important pawpaw producers in Africa namely Nigeria, South Africa, Mozambique and Congo reports any export activity. Watermelon (Citrullus lanatus), a vine-like flowering plant, is a plant species 
in the flowering plant family called Cucurbitaceae. Though watermelon is a highly cultivated fruit worldwide, it originated in West Africa. It has more than 1000 varieties. The global production of watermelons as at 2017 was 118 million tonnes, with China alone accounting for $67 \%$ of the total [1].

Generally, fruit peels contain organic compounds such as cellulose, hemicellulose, pectin substances (complex heteropolysaccharides containing galacturonic acid, arabinose, galactose, and rhamnose), chlorophyll pigments, and some other low molecular weight compounds [2], [3]. Galacturonic acid which has carboxyl functional group could make pectin substances a strong metal adsorbent in aqueous solutions [4]. Thus, the functional groups present in the structure of the adsorbent contribute to the effectiveness of the adsorbent as an adsorber. It was reported by [5], that banana peel is a good source of pectin (10-21\%), lignin (6-12\%), cellulose (7.6-9.6\%), hemicelluloses (6.4-9.4\%), and galactouroninc acid. Furthermore, the pectin extracted from banana peel also contains glucose, galactose, arabinose, rhamnose, and xylose [6]. These contributed to the interest of various researchers in investigation of banana peel as adsorbent of oil from crude oil contaminated water [7] [8] [9]. In the study of the use of banana peels for oil spill removal by Alaa El-Din et al. [9], FTIR analysis of the banana peel was carried out to drive home the effectiveness of banana peel as the adsorbent. FTIR spectroscopy is nondestructive technique for materials analysis and used in the laboratory for over seventy years. Infrared absorption spectroscopy is the study of interaction of infrared radiation with matter as a function of photon frequency. FTIR provides specific information about the vibration and rotation of the chemical bonding and molecular structures, making it useful for analyzing organic materials and certain inorganic materials. An infrared spectrum represents a fingerprint of a sample with absorption peaks which correspond to the frequencies of vibrations between the bonds of the atoms making up the material. Because each different material is a unique combination of atoms, no two compounds produce the exact same infrared spectrum. Therefore, infrared spectroscopy can result in a positive identification (qualitative analysis) of every different kind of material. In addition, the size of the peaks in the spectrum is a direct indication of the amount of material present and running FTIR is essential in that it exposes the functional groups that could be responsible for the excellent sorption properties of the material [10]. Thus, the need to investigate the three agricultural wastes (plantain peel, pawpaw peel and watermelon rind) for possible usage as adsorbent for treating crude oil contaminated water can begin with the humble beginning of carrying out FTIR analysis on the samples of the peels and rind. This is the focus of this study.

\section{MATERIALS AND METHODS}

Agricultural wastes (plantain peel, pawpaw peel and watermelon rind) were obtained from Female hostel, Lagos State University, Epe campus, Lagos State, Nigeria. Distilled water was obtained from various AC outdoor units in Chemical Engineering Department, Lagos state university, Epe campus.

\subsection{Preparation of samples}

Each agricultural waste (plantain peel, pawpaw peel and watermelon rind) obtained was washed with ordinary water to remove suspended particles and then sun dried for seven days. The dried material was then washed thoroughly with distilled water to remove water soluble materials and later dried in the oven at $110^{\circ} \mathrm{C}$ until constant weight was attained. They were removed from the oven and allowed to cool at ambient temperature. The adsorbent material was later crushed into powder form as shown in Figures 1,2 and 3 respectively using mortar and pestle and stored in plastic container.

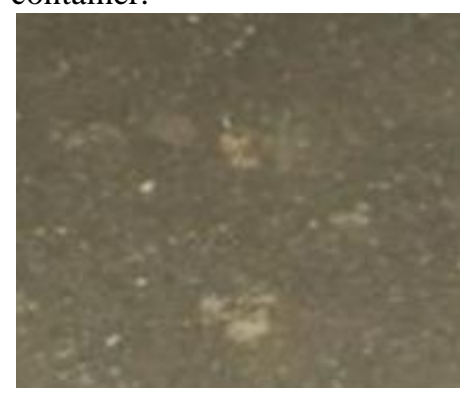

Figure 1. Crushed plantain peel

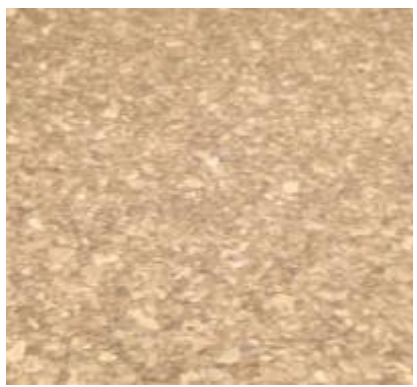

Figure 2. Crushed pawpaw peel

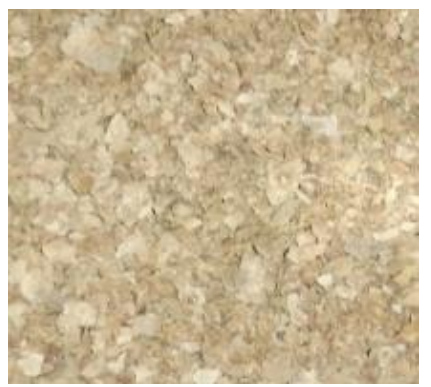

Figure 3. Crushed watermelon rind

Akinyemi et al, 2020 2 www.etrj.com.ng (C) 2020 Faculty of Engineering, Lagos State University, Ojo. Nigeria. All rights reserved. 


\subsection{Fourier Transform Infrared (FTIR) Analysis}

Pure sample of each of the agricultural waste adsorbent in powder form was analysed using Agilent FTIR spectroscope (range: 4000-650). To do this $1 \mathrm{~g}$ of each pure sample was measured using the weighing balance and analyze with the FTIR spectroscope using ASTM E1252-98 standard method. The FTIR analysis was carried out at the central laboratory of Yaba College of Technology, Lagos, Nigeria. In the FTIR analysis, an Infra Red (IR) light source passed through the sample onto a detector, which precisely measures the amount of light absorbed by the sample. The absorbance created a unique spectral fingerprint that was used to identify the molecular structure of the sample and determine the exact quality of a particular compound in the sample.

\section{RESULTS}

Figure 4 showed the FTIR spectrum of pure plantain peel sample. The band in the region of broad strong peak (low) $3265.1 \mathrm{~cm}^{-1}$ indicates the presence of a stretching hydroxyl group $(\mathrm{O}-\mathrm{H}$ stretch, hydrogen bonded) and implied the existence of high concentration of hydroxyl group of polymeric compounds such as lignin or pectin that contains the functional groups of alcohols, phenols and carboxylic acids. The band at $2922.2 \mathrm{~cm}^{-1}$ which is a medium peak indicates a C-H stretching of alkane. The medium band $1595.3 \mathrm{~cm}^{-1}$ indicates a $\mathrm{C}=\mathrm{C}$ stretching (in ring) and $\mathrm{N}-\mathrm{H}$ bending in amine. The medium band at $1375.4 \mathrm{~cm}^{-1}$ indicates $\mathrm{O}-\mathrm{H}$ bending which is the presence of alcohol and phenol while the medium band at $1241.2 \mathrm{~cm}^{-1}$ indicates stretching vibrations of C-N bond of aliphatic amine. The strong band at 1148.0 $\mathrm{cm}^{-1}$ indicates C-O stretching of tertiary alcohol. The strong band at $1073.5 \mathrm{~cm}^{-1}$ indicates $\mathrm{C}-\mathrm{O}$ stretching of primary alcohol. The strong bands at $998.9 \mathrm{~cm}^{-1}$ with low transmittance and strong band $857.3 \mathrm{~cm}^{-1}$ indicate $\mathrm{C}=\mathrm{C}$ bending and $\mathrm{C}-\mathrm{H}$ bending respectively. The $\mathrm{C}=\mathrm{C}$ bending could be attributed to the presence of substituted alkenes in the product and the $\mathrm{C}-\mathrm{H}$ could be attributed to $\mathrm{C}-\mathrm{H}$ bending of crystalline cellulose and $\mathrm{C}-\mathrm{H}$ bending of cellulose, hemicelluloses or lignin polymer. The strong band observed at around $760.4 \mathrm{~cm}^{-1}$ can be attributed to $\mathrm{C}-\mathrm{H}$ bending of aromatic groups. This is in agreement with findings of other researchers [10]. The hydroxyl group and the C-O stretches could have come from the cellulose, hemicelluloses, pectin and lignin compounds in the plantain peel. This is in agreement with findings of other researchers [11][12][13].

Figure 5 showed the FTIR spectrum of pure pawpaw peel sample. The broad band in the region $3265.1 \mathrm{~cm}^{-1}$ which is a strong peak with low transmittance indicates the presence of a stretching hydroxyl $(\mathrm{O}-\mathrm{H})$ group representing presence of high concentration of hydroxyl group of intermolecular bonded polymeric compounds such as lignin or pectin that contains the functional groups of alcohols, phenols and carboxylic acids. The medium band at $2914.8 \mathrm{~cm}^{-}$ ${ }^{1}$ and medium bands at $2847.7 \mathrm{~cm}^{-1}$ indicate a C-H stretching of alkanes. The strong band in the region $1617.7 \mathrm{~cm}^{-1}$ indicates $\mathrm{C}=\mathrm{C}$ stretching of $\alpha, \beta$-unsaturated ketone. The medium bands at $1408.9 \mathrm{~cm}^{-1}$ indicates $\mathrm{O}-\mathrm{H}$ bending of carboxylic acid and the medium bands at $1371.7 \mathrm{~cm}^{-1}$ indicate $\mathrm{O}-\mathrm{H}$ bending of alcohol. The medium band at 1315.8 $\mathrm{cm}^{-1}$ indicates $\mathrm{O}-\mathrm{H}$ bending functional group of phenol while medium $1233.7 \mathrm{~cm}^{-1}$ indicates stretching vibrations of C-N bond of aliphatic amine. The strong peak $1099.6 \mathrm{~cm}^{-1}$ indicates a C-O stretch of secondary alcohol and

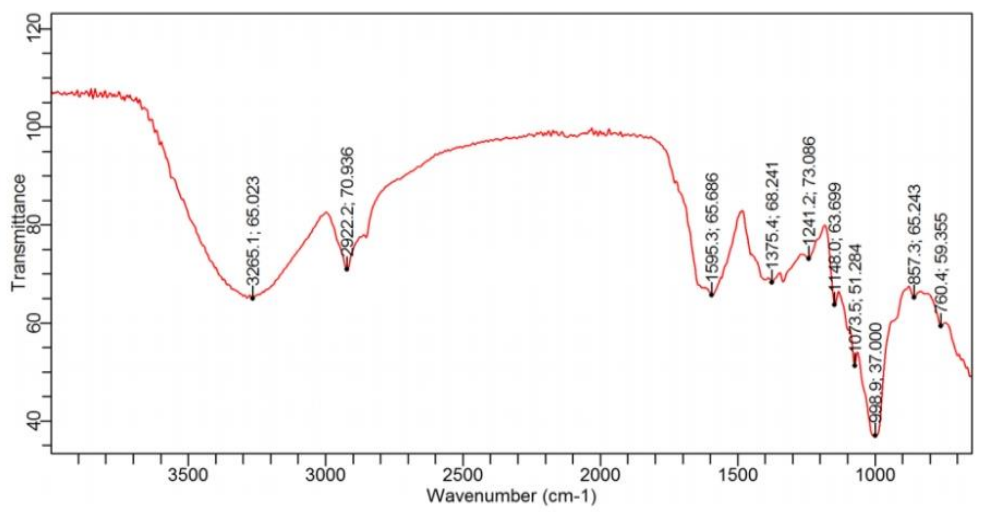

Figure 4 FTIR spectrum of plantain 


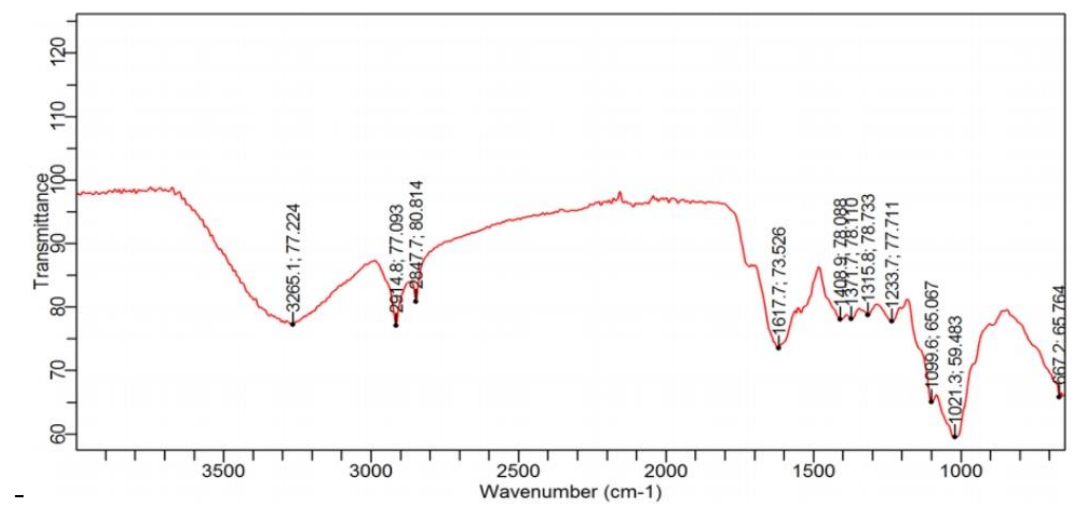

Figure 5. FTIR spectrum of pawpaw

aliphatic ether which can be attributed to presence of lignin. The very strong peak $1021.3 \mathrm{~cm}^{-1}$ (low transmittance) indicates a $\mathrm{C}=\mathrm{C}$ bend. The strong band at $667.2 \mathrm{~cm}^{-1}$ can be assigned to $\mathrm{C}=\mathrm{C}$ bending substituted alkene group. The hydroxyl group and the $\mathrm{C}-\mathrm{O}$ stretches could have come from the cellulose, hemicellulose and lignin compounds in the pawpaw peel. This is in agreement with findings of other researchers [11].

Figure 6 showed the FTIR spectrum of pure watermelon rind sample. The medium broad band at $3317.3 \mathrm{~cm}^{-1}$ indicates an $\mathrm{O}-\mathrm{H}$ stretching of alcohol which implied that high concentration of hydroxyl group of intermolecular bonded polymeric compounds such as lignin or pectin that contains the functional groups of alcohols, phenols and carboxylic acids. The medium band at $2914.8 \mathrm{~cm}^{-1}$ and medium bands at $2847.7 \mathrm{~cm}^{-1}$ indicate a C-H stretching of alkanes. The band at $1736.9 \mathrm{~cm}^{-1}$ which appearance is influenced by conjugation and ring size indicates $\mathrm{C}=\mathrm{O}$ stretching vibrations of carboxylic groups which can be due to the presence of carboxylic acids or their esters. This is in agreement with observations of previous researchers [10]. The medium bands at $1591.6 \mathrm{~cm}^{-1}$ indicates $\mathrm{C}=\mathrm{C}$ stretching (in ring). The medium bands at $1401.5 \mathrm{~cm}^{-1}$ indicates $\mathrm{O}-\mathrm{H}$ bending of carboxylic acid. The medium bands at $1319.5 \mathrm{~cm}^{-1}$ indicates $\mathrm{O}-\mathrm{H}$ bending of phenol while the strong band at $1099.6 \mathrm{~cm}^{-1}$ indicates $\mathrm{C}-\mathrm{O}$ stretching of secondary alcohol and aliphatic ether. The strong $1013.8 \mathrm{~cm}^{-1}$ indicates $\mathrm{C}-\mathrm{O}$ stretching (lignin band). The medium bands at $894.6 \mathrm{~cm}^{-1}$ indicates out-of-plane $\mathrm{C}-\mathrm{H}$ bending. The hydroxyl group (O-H stretch) and the $\mathrm{C}-\mathrm{O}$ stretches could have come from the cellulose, hemicellulose and lignin compounds in the watermelon rind which is in agreement with findings of Li et al. [11]. Furthermore, the carbonyl functional group $(\mathrm{C}=\mathrm{O}$ stretch $)$ confirmed presence of hemicelluloses in the watermelon rind peel in agreement with findings of other researchers [9].

The presence of various peaks due to different functional groups in the three tested agricultural wastes indicates the complex nature of the waste products and the tendency for them to act as good adsorbent. This is in agreement with the observation of [10]. Comparatively, all the three products analysed contained $\mathrm{O}-\mathrm{H}$ stretching, $\mathrm{O}-\mathrm{H}$ bending, $\mathrm{C}=\mathrm{C}$ stretching, $\mathrm{C}-\mathrm{H}$ stretching, $\mathrm{C}-\mathrm{H}$ bending and $\mathrm{C}-\mathrm{O}$ stretching functional group which implies all the three products contain the functional groups relating to hemicellulose, cellulose and pectin which are important components in biological adsorbents. Thus, it can be said that the presence of the functional groups relating to hemicellulose, cellulose and pectin in the three tested agricultural waste just as it was observed for banana peel by previous researchers [9] will make them suitable as adsorbent for removal of crude oil from contaminated water. Furthermore, $\mathrm{N}-\mathrm{H}$ can only be found in plantain peel which implies that amine with this kind of functional group could only be found in the plantain peel and not in the other agricultural waste products. Similarly, $\mathrm{C}=\mathrm{O}$ functional group could be found in watermelon rind alone which implies that the watermelon rind contains hemicelluloses with certain carboxylic acids or their esters that are not in the other agricultural waste. This will definitely have impact on the ability of the watermelon rind as an adsorptive substance. Furthermore, it was observed that only plantain peel and pawpaw peel have the $\mathrm{C}-\mathrm{N}$ stretch functional group which implied the possibility of the pawpaw and plantain peels to contain some amine compounds that are not present in the watermelon rind. Also, $\mathrm{C}=\mathrm{C}$ bend functional group was only found in plantain and pawpaw peels which could be the possibility of the presence of substituted alkenes among the compounds in the plantain and pawpaw peels. The presence of compounds with these functional 


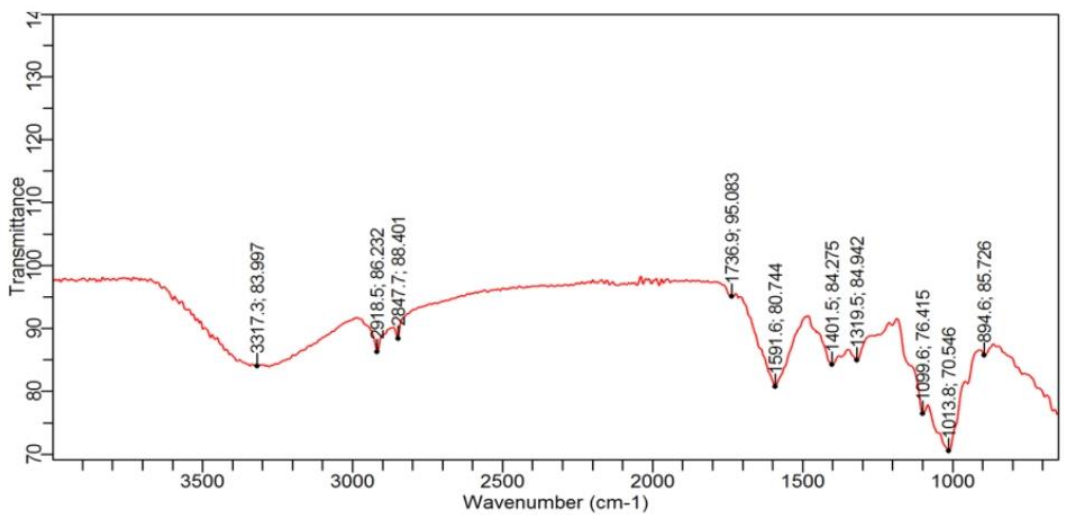

Figure 6. FTIR spectrum of watermelon

groups in plantain and pawpaw peels will have impact on the effectiveness of the two products as adsorbent when compare with watermelon rind.

\section{CONCLUSION}

In view of the world production of plantain peel, pawpaw peel and watermelon rind, they could be recognized as promising crop-based material available for exploring alternative uses. The three agricultural wastes were dried, grounded into powder form and the products analysed using FTIR. All the three products were found to contain O-H stretching, $\mathrm{O}-\mathrm{H}$ bending, $\mathrm{C}=\mathrm{C}$ stretching, $\mathrm{C}-\mathrm{H}$ stretching, $\mathrm{C}-\mathrm{H}$ bending and $\mathrm{C}-\mathrm{O}$ stretching functional groups which implied all the agricultural wastes contain hemicellulose, cellulose and pectin - important components of biological adsorbents. Comparatively, N-H was only found in plantain peel which implies that amine with this kind of functional group could only be found in the plantain peels. Similarly, $\mathrm{C}=\mathrm{O}$ functional group could be found in watermelon rind alone which implies that the watermelon rind contains specific hemicelluloses not in the other two products. Furthermore, it was observed that only plantain peel and pawpaw peel have the $\mathrm{C}-\mathrm{N}$ stretch and $\mathrm{C}=\mathrm{C}$ bend functional groups which implied pawpaw and plantain peels contain some amine and substituted alkenes compounds that are not present in the watermelon rind. These proven capacities of plantain peel, pawpaw peel and watermelon rind provides a favorable platform to researchers to work on and to come out with a sound technology applicable for removal of crude oil from crude oil contaminated water. Furthermore, the technology would bring an additional value to these agricultural wastes, enhancing the fruit industry and the use of these native agricultural materials as adsorbents will lead to cost efficiency and reduce operational cost in crude oil contaminated water treatment.

\section{REFERENCES}

[1] FAOSTAT (2018). United Nations Food and Agriculture Organization, Corporate Statistical Database, Roma, Italy, Retrieved 25 August 2019.

[2] Reddad Z., Gerente C., Andres Y., Le Cloirec P. (2002). Modeling of single and competitive metal adsorption onto a natural polysaccharide. Environ. Sci. Technol. 2002; 36:2242-2248. DOI: 10.1021/es010237a.

[3] Xiaomin L., Yanru T., Zhexian X., Yinghui L., Fang L. (2007). Study on the preparation of orange peel cellulose adsorbents and biosorption of Cd2+rom aqueous solution. Sep. Purif. Technol. 2007; 55:69-75. DOI: 10.1016/j.seppur.2006.10.025.

[4] Saeed A., Akhter M. W., Iqbal M. (2005). Removal and recovery of heavy metals from aqueous solution using papaya wood as a new biosorbent. Sep. Purif. Technol. 2005; 45:25-31. DOI: 10.1016/j.seppur.2005.02.004. 
[5] Mohapatra D., Mishra S., Sutar N. (2010). Banana and its by-product utilization; an overview. J. Sci. Ind. Res. 2010; 69:323-329.

[6] Emaga T. H., Robert C., Ronkart S. N., Wathelet B., Paquot M. (2008). Dietary fibre components and pectin chemical features of peels during ripening in banana and plantain varieties. Bioresour. Technol. 2008; 99:4346-4354. DOI: 10.1016/j.biortech.2007.08.030.

[7] El-Nafaty, U., Muhammad, I. and Abdulsalam, S. (2013). Biosorption and Kinetic Studies on Oil Removal from Produced Water Using Banana Peel. Civil and Environmental Research (IITE), 3(7), pp. 125-135.

[8] Aliyu U. M., El-Nafaty U.A. Muhammad I.M. (2015). Oil removal from crude oil polluted water using banana peel as sorbent in a packed column Journal of Natural Sciences Research, Vol.5, No.2, pp 157-162.

[9] Alaa El-Din G., Amer A. A., Malsh G. and Hussein M. (2017). Study on the use of banana peels for oil spill removal. Alexandria Engineering Journal, pp 1- 8. doi.0rg/10.1016/j

[10] Muntaka D., Zakariyya U. Z., and Maje A. H. (2018). Cationic Dyes Removal Using Low-Cost Banana Peel Biosorbent. American Journal of Materials Science 2018, 8(2): 32-38 DOI: 10.5923/j.materials.20180802.02

[11] Li X., Sun C., Zhou B. and He Y. (2015). Determination of Hemicellulose, Cellulose and Lignin in Moso Bamboo by Near Infrared Spectroscopy. Scientific Report, 5:17210, DOI: 10.1038/srep1721

[12] Kkiu A., Buddhi C. W. and Min-Ho Y. (2013). Banana Peel: A Green Solution for Metal Removal from Contaminated Waters. Korean J Environ Agric 32(2), pp. 108-116 http://dx.doi.org/10.5338/KJEA.2013.32.2.108

[13] Deshmukh P. D., Khadse G. K., Shinde V. M. and Labhasetwar P. (2017). Cadmium Removal from Aqueous Solutions Using Dried Banana Peels as An Adsorbent: Kinetics and Equilibrium Modeling. Journal of Bioremediation \& Biodegradation 8(3); doi: 10.4172/2155-6199.1000395, pp. 1-7. 